\title{
Depressive symptoms in schizophrenia: a study in hospitalized patients
}

\author{
ML Libutti, F Grimaldi, L Perna, A Franco, EL Di Caprio \\ Department of Psychiatry, First Medical School, University of Naples, Italy
}

The occurrence of depressive symptoms in schizophrenic patients hospitalized for an acute psychotic episode has been repeatedly reported in the literature, but the estimates of the prevalence of these symptoms have been very inconsistent, with values ranging from $19-45 \%$ (Leff, 1988). This is clearly related to the variability of the patient samples assessed and of the depressive symptoms considered.

It is commonly held that depressive symptoms often follow the course of psychotic ones, remitting with the resolution of the acute psychotic episodes (Green, 1990). It is recognized, however, that in a minority of patiento, depression may persist after resolution of the psychotic episode, which accounts for part of the cases of 'post-psychotic' depression. The proportion of these last cases is variously estimated from $9-22 \%$.

We carried out a study of 95 patients (53 males and 42 females, age range $16-54$ years, mean \pm SD $27.9 \pm 7.8$ ), consecutively admitted to the inpatient ward of the Department of Psychiatry of the First Medical School of Naples University from January 1, 1986 and onwards.

All these patients were assessed using the CPRS (Asberg et al, 1978) on admission and on discharge (remission of the psychotic episode) from the ward. The duration of the hospital stay of these subjects ranged from 1-103 days (mean \pm SD $24.7 \pm$ 20.5). All of them were treated with neuroleptics (from $60-800 \mathrm{mg} / \mathrm{eq}$ of chlorpromazine/day). No patient was treated with antidepressants.

For the purpose of the study, we used a subscale of CPRS including the items 'depressed mood', 'depressive thoughts', 'suicidal ideas' and 'slowness of movements'.

The percentage of patients presenting at least two of the above symptoms on admission was $38.9 \%$, which is a frequency very close to that reported by Siris et al (1987) and Leff et al (1988). Of these patients, $46.8 \%$ showed on discharge a complete remission of depressive symptoms, whereas $37.5 \%$ presented a partial remission and $13.5 \%$ no remission.

These figures support the view that depressive symptoms are frequently part of the clinical picture of schizophrenia, and that they usually follow the course of psychotic ones.

\section{References}

Asberg M, Montgomery SA, Perris C, Schalling D, Sedvall G (1978) Comprehensive Psychopathological Rating Scale: CPRS. Acta Psychiatr Scand (suppl) 271, $5-27$

Green MF, Nuechterlein KH, Ventura J, Minta J (1990) The temporal relationship between depressive and psychotic symptoms in recent onset schizophrenia. $\mathrm{Am} \mathrm{J}$ Psychiatr 147, 179-182

Leff J, Tress K, Edwards B (1988) The clinical course of depressive symptoms in schizophrenia. Schizophr Res $1,25-30$

Möller HJ, von Zerssen D (1982) Depressive states occurring during the neuroleptic treatment of schizophrenia. Schizophr Bull 8, 109-117

Siris SG, Morgan V, Fagerstrom R, Rifkin A, Cooper TB (1987) Adjunctive imipramine in the treatment of postpsychotic depression. Arch Gen Psychiatry 44, $533-539$ 